\title{
The chemistry of the atmosphere and its perturbations through human activities
}

\author{
Jack G. Calvert \\ Senior Research Associate, The National Center for Atmospheric Research, Boulder, CO, USA
}

\begin{abstract}
The chemistry of the atmosphere results from a complex series of reactions that involve many atmospheric trace gases and that are initiated through sunlight absorption by ozone, formaldehyde and other trace gases. Within the troposphere, this chemistry forms ozone and many highly reactive intermediates and molecules including acids, peroxides, and other undesirable products. However, in contrast, stratospheric chemistry leads to the destruction of natural stratospheric ozone, our protective shield from short ultraviolet radiation at the earth's surface. This results when halocarbons, relatively innocuous, unreactive compounds in the troposphere, are released at the surface of the earth and are ultimately transported to the stratosphere. Here sunlight dissociates them into highly reactive molecular fragments that start a chain of chemical events which destroy stratospheric ozone.
\end{abstract}

Atmospheric scientists, industrial and academic scientists and engineers of other disciplines, as well as the general public, are becoming more aware of the importance of understanding the changes which are occurring in the atmosphere as a result of human activities. We are all interested in minimizing the occurrence of surprises such as the 'ozone hole,' forest damage, etc. The leaders of our countries require advice in designing scientifically sound yet economically realistic solutions to the many problems which result from the anthropogenic perturbations that we induce on our natural system. Clearly the knowledge of atmospheric chemistry as derived from both fundamental and applied chemical studies by scientists from many disciplines will form the basis for sound scientific solutions to these problems.

\section{INTRODUCTION}

Many of us picture the earth's life-giving atmosphere, the oxygen, nitrogen, carbon dioxide, water, methane, and the multitude of other trace gases it contains, as a relatively unchanging, indestructible gaseous mixture. We have considered its relative vastness to be an infinite sink for any and all waste products of our civilization which we might wish to vent into it. That the relatively finite emissions from human activity might noticeably perturb its properties, particularly in a global sense, is still not accepted readily by some people. However, we recognize today, particularly in urban areas with a high density of population, indisputable evidence of some very significant perturbations which result from human activity: the generation of high levels of ozone, the high acidity of rain, the density of the haze, the irritation of our eyes, evidence of stress on plants and trees, etc. Some environmental problems are less tangible than those of urban pollution, and surprisingly, they are not yet fully accepted as major concerns by some of the public. For example, the notion that the very unreactive chlorofluorocarbons (CFCs) released at the surface of the earth can lead to serious destruction of our protective stratospheric ozone layer is debated in some circles as an unsubstantiated theory. However the appearance of the "ozone hole" over Antarctica in recent years has renewed interest of many previous skeptics in the possible truth in the scientific theories of stratospheric ozone destruction.

Today, atmospheric scientists, industrial and academic scientists and engineers of many disciplines are becoming more aware of the importance of understanding the changes which are occurring in the atmosphere as a result of human activities. We are all interested in minimizing the occurrence of surprises such as the "ozone hole", forest damage, etc. The leaders of our countries require advice in designing scientifically sound yet economically realistic solutions to the many problems which result from the perturbations that we induce on our natural system. Clearly the knowledge of atmospheric chemistry as derived from both fundamental and applied chemical studies by scientists from many disciplines can form 
the basis for sound scientific solutions to these problems.

In this discussion, we will review briefly the chemistry of the atmosphere and attempt to identify critical elements which can alter this chemistry. The scope of our present discussions will be necessarily limited to only a few of the perturbations in our atmosphere. In addition, some specific contributions will be identified that IUPAC scientists can make in our continued search for understanding of atmospheric chemistry and in the control of harmful air pollution.

\section{THE CHEMISTRY OF THE ATMOSPHERE}

Perturbations of the atmosphere by human activity which have been observed have some common features: All involve in one way or another the reactions of highly reactive transient species such as the hydroxy, the hydroperoxy, $\mathrm{O}-, \mathrm{Cl}-$, and $\mathrm{Br}$-atom and other species. These are not standard chemical reagents which we chemists can pour out of a bottle. They are usually present in the atmosphere at very small concentrations (mole ratios of $10^{-9}$ to $10^{-12}$ ). As a consequence the study of atmospheric chemistry usually demands highly specialized equipment for the measurements which is often complex and difficult to develop. We will consider here two examples of major perturbations induced in the chemistry of the atmosphere by anthropogenic input: A) stratospheric ozone depletion; and B) tropospheric ozone build-up. In section C a few other examples will be considered briefly.

A. Stratospheric ozone depletion: 1) Chlorofluorocarbons. Ozone is a strong absorber of sunlight of wavelengths less than $320 \mathrm{~nm}$ and as such it forms a protective shield against the penetration of harmful short wavelength light to the earth's surface. In 1974 Molina and Rowland sounded a clear warning that the chlorofluorocarbons could induce ozone removal in the stratosphere. Subsequent extensive studies have supported their hypothesis. Scientists in both the fundamental and applied areas have helped in our understanding of this highly complex environmental problem and in its general acceptance by both government and industry leaders. The development of control policies and the CFC industries' acceptance of them has resulted in their curtailment of the manufacture of CFC chemicals and in their redesign of suitable replacement compounds. Consider briefly here the interesting chemistry of stratospheric ozone depletion.

Ozone absorption of sunlight in the atmosphere is the driving force for the many chemical changes which occur within it. $\mathrm{O}_{3}$ is formed in the earth's stratosphere from molecular oxygen. The very short ultraviolet wavelengths present in the solar radiation which reaches the upper atmosphere of the earth $(\lambda<$ $245 \mathrm{~nm}$ ) are absorbed by molecular oxygen to form excited electronic states of $\mathrm{O}_{2}$. These dissociate rapidly to form both ground state, $\mathrm{O}\left({ }^{3} \mathrm{P}\right)$, and excited state, $\mathrm{O}\left({ }^{1} \mathrm{D}\right)$ atoms.

(1) $\mathrm{O}_{2}\left({ }^{3} \Sigma_{\mathrm{g}}\right)+h v(\lambda<240 \mathrm{~nm}) \rightarrow\left[\mathrm{O}_{2}\left({ }^{3} \Sigma_{\mathrm{u}}+{ }^{3} \Sigma_{\mathrm{u}}^{-},{ }^{3} \Pi_{\mathrm{u}}\right)\right] \rightarrow \mathrm{O}\left({ }^{1} \mathrm{D},{ }^{3} \mathrm{P}\right)+\mathrm{O}\left({ }^{3} \mathrm{P}\right)$

$\mathrm{O}\left({ }^{3} \mathrm{P}\right)$ atoms react in large part with molecular oxygen in (2) to form ozone which accumulates in the stratosphere in a band extending from about 10 to $35 \mathrm{~km}$ above the earth's surface.

(2) $\mathrm{O}\left({ }^{3} \mathrm{P}\right)+\mathrm{O}_{2}+\left(\mathrm{N}_{2}, \mathrm{O}_{2}\right) \rightarrow \mathrm{O}_{3}+\left(\mathrm{N}_{2}, \mathrm{O}_{2}\right)$

Of course ozone does not build up indefinitely, because it is destroyed by sunlight absorption $(\lambda<320$ $\mathrm{nm})$ in reaction (3), and by various reactions with transient species generated in the atmosphere $\left(\mathrm{OH}, \mathrm{HO}_{2}\right.$, $\mathrm{NO}, \mathrm{Cl}, \mathrm{Br}, \mathrm{O}$-atoms, etc), reactions (4)-(10).
3) $\mathrm{O}_{3}+h v(\lambda<320 \mathrm{~nm}) \rightarrow \mathrm{O}_{2}\left({ }^{1} \Delta_{\mathrm{g}}\right)+\mathrm{O}\left({ }^{1} \mathrm{D}\right)(+\mathrm{M}) \rightarrow \mathrm{O}\left({ }^{3} \mathrm{P}\right)(+\mathrm{M})$
4) $\mathrm{O}_{3}+\mathrm{O}\left({ }^{3} \mathrm{P}\right) \rightarrow 2 \mathrm{O}_{2}$
5) $\mathrm{O}_{3}+\mathrm{NO} \rightarrow \mathrm{O}_{2}+\mathrm{NO}_{2}$
6) $\mathrm{NO}_{2}+\mathrm{O}\left({ }^{3} \mathrm{P}\right) \rightarrow \mathrm{NO}+\mathrm{O}_{2}$
7) $\mathrm{O}_{3}+\mathrm{OH} \rightarrow \mathrm{O}_{2}+\mathrm{HO}_{2}$
8) $\mathrm{O}_{3}+\mathrm{HO}_{2} \rightarrow \mathrm{OH}+2 \mathrm{O}_{2}$
9) $\mathrm{O}_{3}+\mathrm{Cl}$ (or $\left.\mathrm{Br}\right) \rightarrow \mathrm{ClO}$ (or $\left.\mathrm{BrO}\right)+\mathrm{O}_{2}$
10) $\mathrm{ClO}$ (or $\mathrm{BrO})+\mathrm{O}\left({ }^{3} \mathrm{P}\right) \rightarrow \mathrm{Cl}($ or $\mathrm{Br})+\mathrm{O}_{2}$

The $\mathrm{OH}$ radicals are formed largely by the reactions of $\mathrm{O}(\mathrm{D})$ with $\mathrm{H}_{2} \mathrm{O}$ in reaction (11), and $\mathrm{HO}_{2}$ by reactions of $\mathrm{OH}$, sequence (12) involving $\mathrm{CH}_{4}$, and $\mathrm{CO}$ in (13):: 
11) $\mathrm{O}\left({ }^{1} \mathrm{D}\right)+\mathrm{H}_{2} \mathrm{O} \rightarrow 2 \mathrm{OH}$

12) $\mathrm{OH}+\mathrm{CH}_{4} \rightarrow \mathrm{H}_{2} \mathrm{O}+\mathrm{CH}_{3} \mathrm{O}_{2} \rightarrow \mathrm{CH}_{3} \mathrm{O}\left(+\mathrm{O}_{2}\right) \rightarrow \mathrm{CH}_{2} \mathrm{O}+\mathrm{HO}_{2}$

13) $\mathrm{OH}+\mathrm{CO}\left(+\mathrm{O}_{2}\right) \rightarrow \mathrm{HO}_{2}+\mathrm{CO}_{2}$

Cycles of the reactions (5)-(6), (7)-(8), and (9)-(10) can repeat to destroy several molecules of $\mathrm{O}_{3}$ before the catalyst molecule, $\mathrm{NO}, \mathrm{NO}_{2}, \mathrm{OH}, \mathrm{HO}_{2}, \mathrm{Cl}, \mathrm{Br}, \mathrm{ClO}$ or $\mathrm{BrO}$, is destroyed by radical-radical, radical-NO, radical- $\mathrm{NO}_{2}$ or other reactions. Each of these cycles contributes to ozone destruction, and the concentration to which ozone builds in the stratosphere is determined by the net rate of its formation and destruction by the various pathways.

On a mole per mole basis, bromine-containing compounds, although less abundant in the atmosphere than those of chlorine, are more effective than chlorine in depleting ozone. Br-atoms are released more rapidly than $\mathrm{Cl}$-atoms with increasing altitude (because of the larger absorption cross sections of the $\mathrm{Br}$ compounds), and a greater fraction of the inorganic bromine remains in active forms $(\mathrm{Br}, \mathrm{BrO})$ than the chlorine analogues.

The chlorofluorocarbons (CFCs) can play a role in stratospheric ozone destruction through the enhancement of the $\mathrm{Cl}$-atom concentration in the stratosphere (Molina and Rowland, 1974). When released into the atmosphere they are essentially chemically inert in the troposphere, but as they are slowly mixed into the stratosphere, they absorb short wavelength solar radiation, are dissociated to form $\mathrm{Cl}$-atoms and other molecular fragments, and the catalytic cycle of $\mathrm{O}_{3}$ destruction (9)-(10) is enhanced. Of the primary sources of chlorine entering the atmosphere, $82 \%$ is now from CFC's and other human-made chemicals.

Extensive studies of the "ozone hole" in the Antarctic atmosphere show that under certain conditions heterogeneous sources of $\mathrm{Cl}$-atoms can be more important than the homogeneous reactions outlined (Molina, 1994). Polar stratospheric cloud (PSC) particles have been identified as an essential component of the CFC-induced polar ozone-depletion mechanism. "Inert" reservoirs of chlorine $\left(\mathrm{HCl}\right.$ and $\left.\mathrm{ClONO}_{2}\right)$ can be converted to $\mathrm{Cl}_{2}$ (and other readily photolyzed Cl-products) on PSC particles in reactions (14)-(19):

(14) $\mathrm{HCl}+\mathrm{ClONO}_{2}$ (on $\mathrm{PSC}$ particles) $\rightarrow \mathrm{Cl}_{2}(\mathrm{~g})+\mathrm{HNO}_{3}$ (s)

(15) $\mathrm{HCl}+\mathrm{HOCl}$ (on $\mathrm{PSC}$ particles) $\rightarrow \mathrm{Cl}_{2}(\mathrm{~g})+\mathrm{H}_{2} \mathrm{O}$ (s)

(16) $\mathrm{HCl}+\mathrm{N}_{2} \mathrm{O}_{5}$ (on $\mathrm{PSC}$ particles) $\rightarrow \mathrm{ClNO}_{2}(\mathrm{~g})+\mathrm{HNO}_{3}$ (s)

(17) $\mathrm{N}_{2} \mathrm{O}_{3}+\mathrm{H}_{2} \mathrm{O}\left(\mathrm{H}_{2} \mathrm{SO}_{4}\right.$ aerosol $) \rightarrow 2 \mathrm{HNO}_{3}$

(18) $\mathrm{Cl}_{2}+h v(\lambda<470) \rightarrow \mathrm{Cl}+\mathrm{Cl}$

(19) $\mathrm{ClNO}_{2}+h v(\lambda<370 \mathrm{~nm}) \rightarrow \mathrm{Cl}+\mathrm{NO}_{2}$

During the Antarctic spring ozone reductions have become increasingly serious, decreasing from 325 Dobson units to 145 in 1992. As a direct result the harmful erythemal uv-radiation reaching the earth near Antarctica has increased by $150 \%$ during the period. The concentration of reactive chlorine species $(\mathrm{Cl}$, $\mathrm{ClO}$ ) as measured in the polar stratosphere shows an inverse correlation with the $\mathrm{O}_{3}$ concentration, as expected with the importance of reactions (9), (10), and (14-19).

Changes in atmospheric chemistry can be induced by the occurrence of some natural processes such as large volcanic eruptions. The eruption of Mt. Pinatubo in 1991 led to a large increase in sulfate aerosols in the lower stratosphere. Significant ozone depletion was observed throughout the globe which is believe to have occurred from the removal of the active nitrogen storage compound $\mathrm{N}_{2} \mathrm{O}_{5}$ which is enhanced on sulfuric acid aerosols as well as PSC particles (reaction (17).

A large body of scientific evidence confirms the essential correctness of our current understanding of the general features of the stratospheric ozone loss which we have considered briefly here. In the recent WMO report (1995), this evidence is reviewed. The observed trends in the atmospheric concentrations of the major ozone depleting substances are in general accord with the expectations based upon the controls achieved through the Montreal Protocol and its Amendments and Adjustments. The peak loading of the total $\mathrm{Cl}$ - and Br-containing compounds in the troposphere was expected to occur in 1994 with a stratospheric peak occurring 3-5 years later. Increasing global ozone losses are predicted for the remainder

a The thickness in units of $10^{-3} \mathrm{~cm}$ of that layer which would be formed by the total ozone in a vertical column reduced to a pressure of one atmosphere and $0^{\circ} \mathrm{C}$. 
of the decade, with gradual recovery in the 21 st century.

The accepted strategy to reclaim the stratospheric ozone is based upon the replacement of the CFCs with the hydrochlorofluorocarbons (HCFCs). This has been initiated with the expectation that their higher reactivity with $\mathrm{OH}$-radical will result in the removal of most of these species in the troposphere before transport to the stratosphere can occur. The atmospheric abundances of several HCFCs are increasing as anticipated as the hydrochlorofluorocarbons and hydrofluorocarbons are being manufactured, used and released to the atmosphere. $\mathrm{HCFC}-22\left(\mathrm{HCF}_{2} \mathrm{Cl}\right)$ has been used and observed for years, and HCFC-142b $\left(\mathrm{CF}_{2} \mathrm{ClCH}_{3}\right)$ and $\mathrm{HCFC}-141 \mathrm{~b}\left(\mathrm{CFCl}_{2} \mathrm{CH}_{3}\right)$, now entering the atmosphere, are being monitored. Concentrations of chlorine in the tropospheric HCFCs increased at a rate of 10 pptv/year in 1992. Our concern now is to be sure we have not shifted the ozone depletion problem to one of contamination of the troposphere and our water and soil. The oxidation of the HCFCs will form in the troposphere products such as $\mathrm{CH}_{3} \mathrm{COCl}, \mathrm{CCl}_{2} \mathrm{FCOO}_{2} \mathrm{NO}_{2}, \mathrm{CCl}_{3} \mathrm{CO}_{2} \mathrm{H}, \mathrm{CF}_{3} \mathrm{CO}_{2} \mathrm{H}$, etc. (AFEAS Workshop, 1995).

2) Stratospheric ozone depletion by aircraft emissions. Currently there are extensive studies in several countries which relate to the potential impact of the emissions from supersonic and subsonic aircraft on stratospheric ozone; e.g., see the recent reports of NRC (1993), WMO (1995), and NASA (1995). Of particular concern is the effect of the emissions of nitrogen oxides and aerosols and their precursors from a proposed fleet of several hundred supersonic transports which have been proposed to fly near or in the stratospheric ozone layer. Current models of the effects of $\mathrm{NO}_{\mathrm{x}}$ emissions from subsonic aircraft on the $\mathrm{O}_{3}$ levels in the upper troposphere (Ehhalt and Rohren, 1994; Brasseur, et al., 1995) predict an overall increase in $\mathrm{O}_{3}$ may result from the additional aircraft traffic. However there are many uncertainties in the calculations (e.g., the background levels of $\mathrm{NO}_{x}$ present today) which could alter these predictions. Johnston (1994) has reviewed the history of similar calculations for the stratosphere and concluded that the relatively large ozone column reductions which his original studies predicted using only homogeneous chemistry (including the important reactions (5) and (6)) are far less dramatic when heterogeneous chemistry (removal of active nitrogen compounds) is included. The quantitative characterization of heterogeneous chemistry and its parameterization in predictive models of the atmosphere are difficult, and extra caution will be demanded in deriving realistic predictions of the magnitude and the uncertainties in the effects of aircraft emissions on the stratospheric ozone depletion.

$B$. Tropospheric ozone build-up. Ozone measurements made over a number of years in many countries have shown a steady climb in the tropospheric ozone levels [e.g., see Kley et al. (1994) and Akimoto et al. (1994)]. While the depletion of stratospheric ozone is a major concern, remedies for the build-up of ozone in the troposphere are sought. The generation of high urban ozone concentrations is usually accompanied by other obvious effects, e.g., eye irritation, haze, plant damage, etc. In the Los Angeles, California urban area, this problem, termed "photochemical smog", has been a matter of public concern for over fifty years. A great deal of research has been devoted to the solution of this problem, and there is now a reasonably good understanding of the chemistry of urban ozone development. However proposed solutions to the problem have not eliminated it. Photochemical smog is observed today in most large urban areas of the world, and the methods for its control continue to be discussed. There are interesting differences between the chemistry of the troposphere and that of the stratosphere which lead to generation of ozone in the first case and destruction of ozone in the second. To understand these differences, a brief review of the tropospheric chemistry is in order.

Haagen-Smid and co-workers $(1952,1953)$ recognized in the early 1950 's, and subsequent laboratory and field studies prove, that there are several key ingredients necessary to generate ozone within the troposphere: sunlight, oxides of nitrogen, and reactive hydrocarbons and/or their oxidation products. The photodissociation of $\mathrm{NO}_{2}$ can lead to tropospheric ozone generation through the reactions (20) and (21):

20) $\mathrm{NO}_{2}+h v(\lambda<430 \mathrm{~nm}) \rightarrow \mathrm{O}\left({ }^{3} \mathrm{P}\right)+\mathrm{NO}$

2) $\mathrm{O}\left({ }^{3} \mathrm{P}\right)+\mathrm{O}_{2}\left(+\mathrm{N}_{2}, \mathrm{O}_{2}\right) \rightarrow \mathrm{O}_{3}\left(+\mathrm{N}_{2}, \mathrm{O}_{2}\right)$

5) $\mathrm{NO}+\mathrm{O}_{3} \rightarrow \mathrm{NO}_{2}+\mathrm{O}_{2}$

However the photolysis of $\mathrm{NO}_{2}$ alone cannot cause a build-up of $\mathrm{O}_{3}$, since ozone reacts rapidly with NO in reaction (5). The occurrence of (20) and (2) is always followed by (5) so that for a fixed amount of $\mathrm{NO}_{2}$ in sunlight of a given intensity, within minutes a photostationary state of $\mathrm{O}_{3}$ is reached as given approximately by equation (23): 


\section{1) $\left[\mathrm{O}_{3}\right] \approx\left\{\left[\mathrm{NO}_{2}\right] j_{\mathrm{NO} 2}\right\} /[\mathrm{NO}] k_{5}$}

Here $j_{\mathrm{NO} 2}$ is the apparent first order rate coefficient for $\mathrm{NO}_{2}$ photodissociation in reaction (20). In order to build-up $\mathrm{O}_{3}$ within the troposphere, some additional reactions must occur to regenerate $\mathrm{NO}_{2}$ from NO. It has been shown clearly that the certain key transient species derived from the hydrocarbons and their oxidation products provide this action. One key transient is the hydroxy $(\mathrm{OH})$ radical, formed through the photodissociation of $\mathrm{O}_{3}$ itself in reactions (1a) and the subsequent reaction of the highly excited $\mathrm{O}\left({ }^{1} \mathrm{D}\right)$ atom with water in (11). When $\mathrm{O}_{3}$ is lost in (1a), it can be reformed in (2) following electronic quenching in (22):

1a) $\mathrm{O}_{3}+h v(\lambda<320 \mathrm{~nm}) \rightarrow \mathrm{O}\left({ }^{1} \mathrm{D}\right)+\mathrm{O}_{2}\left({ }^{1} \Delta_{\mathrm{g}}\right)$

11) $\mathrm{O}\left({ }^{1} \mathrm{D}\right)+\mathrm{H}_{2} \mathrm{O} \rightarrow 2 \mathrm{OH}$

22) $\mathrm{O}\left({ }^{1} \mathrm{D}\right)+\mathrm{N}_{2}, \mathrm{O}_{2} \rightarrow \mathrm{O}\left({ }^{3} \mathrm{P}\right)+\mathrm{N}_{2}, \mathrm{O}_{2}$

As a result of the competitive reactions (11) and (22) of the $\mathrm{O}\left({ }^{\prime} \mathrm{D}\right)$-atoms, for a given $\left[\mathrm{O}_{3}\right]$ and solar flux, the rate of generation of $\mathrm{OH}$-radicals increases as the concentration of water in the troposphere increases (relative humidity rises). The success of the $\mathrm{OH}$-radical in building ozone lies in its high reactivity with hydrocarbons and their oxidation products and the formation of hydroperoxy radicals $\left(\mathrm{HO}_{2}\right)$ and many different organic peroxy radicals $\left(\mathrm{RO}_{2}\right)$. These transformations are generalized in reactions (23)-(26):

23) $\mathrm{OH}+\mathrm{RH}\left(+\mathrm{O}_{2}\right) \rightarrow \mathrm{H}_{2} \mathrm{O}+\mathrm{RO}_{2}$

24) $\mathrm{RO}_{2}+\mathrm{NO} \rightarrow \mathrm{RO}+\mathrm{NO}_{2}$

25) $\mathrm{RO}+\mathrm{O}_{2} \rightarrow \mathrm{HO}_{2}+$ Aldehyde or Ketone

26) $\mathrm{HO}_{2}+\mathrm{NO} \rightarrow \mathrm{OH}+\mathrm{NO}_{2}$

In the reaction sequence shown, hydrocarbons (symbolized by $\mathrm{RH}$, where $\mathrm{R}$ is any $\mathrm{C}_{\mathrm{n}} \mathrm{H}_{\mathrm{m}}$ group with $\mathrm{n}>$ 1) react with $\mathrm{OH}$ to form ultimately $\mathrm{RO}_{2}$ and $\mathrm{HO}_{2}$. These rapidly oxidize $\mathrm{NO}$ to $\mathrm{NO}_{2}$, and through $\mathrm{NO}_{2}$ sunlight photolysis in (20) followed by (2), newly regenerated $\mathrm{NO}_{2}$ develops new ozone. As this occurs a new $\mathrm{OH}$ radical is formed to replace the one which reacted in (23), and the repeat of the entire sequence can occur again and again to form more $\mathrm{O}_{3}$ until the $\mathrm{OH}, \mathrm{HO}_{2}$, and $\mathrm{RO}_{2}$ radicals are removed by chain terminating processes. Reactions (27)-(29) are the most common of these:

27) $\mathrm{HO}_{2}+\mathrm{HO}_{2} \rightarrow \mathrm{H}_{2} \mathrm{O}_{2}+\mathrm{O}_{2}$

28) $\mathrm{HO}_{2}+\mathrm{RO}_{2} \rightarrow \mathrm{RO}_{2} \mathrm{H}+\mathrm{O}_{2}$

29) $\mathrm{OH}+\mathrm{NO}_{2} \rightarrow \mathrm{HONO}_{2}$

In an atmosphere which is highly polluted in $\mathrm{NO}_{x}\left(\left[\mathrm{NO}_{\mathrm{x}}\right]=[\mathrm{NO}]+\left[\mathrm{NO}_{2}\right]\right)$, the number of molecules of ozone formed per $\mathrm{NO}_{\mathrm{x}}$ removed is much less that that obtained in less polluted atmospheres. The formation of $\mathrm{O}_{3}$ is a very non-linear, highly complex function of the concentrations of $\mathrm{NO}, \mathrm{NO}_{2}$, the hydrocarbons, as well as their structure and reactivities. When one considers the reactions of the many hundreds of different individual hydrocarbons present in an urban atmosphere, the few generalized reactions above mushroom into many thousands of compound-specific reactions all of which contribute to ozone development. Each individual hydrocarbon and each of its many oxidation products (aldehydes, ketones, alcohols, etc.) react with its own characteristic efficiency to form a brew of different $\mathrm{RO}_{2}$ species. It is not surprising that after 50 years of extensive research on the chemistry of tropospheric ozone generation, there are still unanswered questions on the detailed mechanism.

It is instructive to identify the major differences in the chemical mechanisms which result in stratospheric ozone loss and a tropospheric ozone increase. Of course, the Cl-atom catalyzed reactions induced by the CFCs are peculiar to the stratosphere, for it is only here in the region rich in short wavelength UV-light and high concentration of $O\left({ }^{\prime} D\right)$-atoms (reactive toward CFCs) that the CFCs are decomposed to form $\mathrm{Cl}$-atoms. Some $\mathrm{Cl}$-atoms are formed in the troposphere through the presence and reactions of some less common reactive $\mathrm{Cl}$-containing molecules (e.g., $\mathrm{NOCl}, \mathrm{NO}_{2} \mathrm{Cl}, \mathrm{Cl}_{2}$, etc.). However when formed these $\mathrm{Cl}$-atoms react largely with the non-methane hydrocarbons, peculiar to the troposphere. Like OH-radicals, the Cl-atoms reactions in the troposphere initiate $\mathrm{RO}_{2}$ and $\mathrm{HO}_{2}$ formation, $\mathrm{NO}$ to $\mathrm{NO}_{2}$ conversion, and subsequently $\mathrm{O}_{3}$ formation. The difference seen in the effects of added $\mathrm{NO}_{x}$ in the two regions of the atmosphere arises in several ways. Partly it results from the significant difference in the relative rates of the reactions of $\mathrm{O}\left({ }^{3} \mathrm{P}\right)$ with $\mathrm{O}_{2}$ and $\mathrm{NO}_{2}$ in the two regions of the atmosphere. The former leads to ozone formation while the latter destroys an $\mathrm{NO}_{2}$ molecule, a potential $\mathrm{O}_{3}$ source through reactions 
(20) and (2). The dominant pathway for removal of $\mathrm{O}\left({ }^{3} \mathrm{P}\right)$-atoms in the troposphere is its coupling reaction with molecular oxygen (reaction (2)). Note this reaction is in the third-order region, and the much higher concentration (factor of 13.4) of chaperone molecules $\left(\mathrm{N}_{2}\right.$ and $\mathrm{O}_{2}$ ) in the lower troposphere compared to the mid-stratosphere, favors reaction with $\mathrm{O}_{2}$ rather than the second-order reaction (6) with $\mathrm{NO}_{2}$. The concentration of $\mathrm{NO}_{2}$ molecules is similar in the two atmospheric regions, but differences in temperature and pressure lead to significant differences in the rate coefficients of reactions (2) and (6). The ratio of rates of these reactions in the two regions are: $\left[R_{2} / R_{6}\right]_{\text {rop }} /\left[R_{2} / R_{6}\right]_{\text {strat }} \approx 10^{2}$. Thus $\mathrm{NO}_{2}$ is a more effective catalyst for $\mathrm{O}_{3}$ removal in the stratosphere than in the troposphere. Furthermore, in the polluted troposphere, the competitive reaction (26) of $\mathrm{HO}_{2}$-radicals with $\mathrm{NO}$, leading to $\mathrm{NO}_{2}$ and ultimately to $\mathrm{O}_{3}$ in (20) and (2), is favored over its ozone destroying reaction (8). The abundant reactive hydrocarbons and their oxidation products constitute the major sink for $\mathrm{OH}$-radicals in the troposphere. These reactions form the many peroxy radicals which drive $\mathrm{NO}$ to $\mathrm{NO}_{2}$ in the sequence (23)-(26), and hence lead to $\mathrm{O}_{3}$ generation. Of course, methane, the least reactive hydrocarbon and its oxidation products $\left(\mathrm{CO}, \mathrm{H}_{2}, \mathrm{CH}_{2} \mathrm{O}\right.$, $\mathrm{CH}_{3} \mathrm{O}_{2} \mathrm{H}$, and $\left.\mathrm{CH}_{3} \mathrm{OH}\right)$ are present in the stratosphere, but the rate of generation of $\mathrm{HO}_{2}$ and $\mathrm{CH}_{3} \mathrm{O}_{2}$ radicals from these is a small fraction of that in the troposphere. At the very low water concentration of the stratosphere, $R_{22} \gg R_{11}$, and $\mathrm{OH}$-radical generation is greatly attenuated from that of the troposphere. Thus as the concentration of $\mathrm{NO}_{x}$ impurity is increased, these effects (and others) combine to favor net $\mathrm{O}_{3}$ loss in the stratosphere and net $\mathrm{O}_{3}$ formation in the troposphere.

It has been possible to check key aspects of the ozone generation through detailed measurements within the troposphere itself. In some field studies simultaneous measurements have been made of most of the trace gases, including the highly reactive transient species, $\mathrm{OH}, \mathrm{HO}_{2}$, and $\mathrm{RO}_{2}$, which drive the $\mathrm{O}_{3}$ generation. Since the lifetimes of the radicals are very short (fractions of second to minutes), their rates of formation and their rapid chemical reactions alone determine their concentrations. Meteorology and transport are unimportant for these conditions. It appears from such studies that the mechanisms outlined here are sound, and matches between measured and theoretical radical concentrations are often within the uncertainties in the measurements (e.g., see Cantrell et al., 1993). The computer modeling of the development of ozone, a much longer lived atmospheric component, offers much greater challenges, since the emissions, deposition, and meteorology, as well as the complex chemistry must be incorporated into the modeling system (e.g., see Seinfeld, 1988).

Major efforts have been made in many countries to determine the most cost-effective strategies for tropospheric ozone control. Usually these involve extensive chemical and meteorological measurement programs during high ozone episodes in an urban community. In addition, detailed, time dependent emission inventories of all the important precursors to ozone generation in the region are estimated. These emissions, meteorological and chemical data are then combined in a sophisticated urban air shed model which uses seemingly realistic (but necessarily highly simplified) chemical and transport schemes. The model is then run to test the predictions against measurement at the many measurement sites. Assuming these results are in reasonable agreement, and they often are, the model can then be run using the same meteorological input but with altered emissions, assuming various degrees of control on the $\mathrm{NO}_{\mathrm{x}}$ and hydrocarbon emissions. In principle this information can be used to establish the degree of control necessary to provide the desired regulation of the $\mathrm{O}_{3}$. Many such studies have been made over the years and these continue today in massive field programs designed to understand and control tropospheric ozone.

In spite of the many efforts to control tropospheric ozone build-up, the success has been limited to date. Reductions in ozone have resulted, but the improvements have not been as large as those targeted and expected using the control strategy adopted. Recently a U.S. National Research Council committee studied this problem and identified several possible reasons for the unexpected inefficiency of the adopted controls (NRC, 1991). These include possible errors in the emissions inventories, especially failure to account properly for "super and high emitters", high off-cycle emissions, and auto control system failures in poorly maintained vehicles among the mobile fleet. Remote sensing of the composition of the exhaust of passing automobiles has shown in recent years that about $10 \%$ of the mobile fleet account for $50 \%$ of the on-road hydrocarbon and CO emissions in the several cities which have been studied (Beaton et al., 1995). Another important cause of the limited success of the control programs to date is the probable underestimation of the magnitude of the reactive biogenic hydrocarbon emissions (isoprene, pinenes, etc.) from the trees and foliage of the community developing controls. In the southeastern U.S., and likely in many other regions of the world, these emissions, together with $\mathrm{NO}_{\mathrm{x}}$, can dominate the chemistry of ozone generation. One of the major questions which each community faces in developing $\mathrm{O}_{3}$ control strategies, is: Will the most 
effective control require the reduction of hydrocarbons or nitrogen oxide precursors? Most policies have focused on hydrocarbon emission control (largely from the mobile fleet), since the technology for this is simpler and more economical to apply than that necessary to control $\mathrm{NO}_{\mathrm{x}}$. Since the control of biogenic emissions is neither desirable nor attempted, the control of hydrocarbon emissions from the mobile fleet will have little effect in reducing ozone in those areas rich in biogenic emissions.

Solutions to the tropospheric ozone problem are not straight forward, and we must be careful not to introduce new problems as we solve the old ones. For example, as part of some regulatory plans in certain non-attainment areas of the USA, it has been mandated that a fraction of the cars now using hydrocarbon based fuels in mobile fleets be replaced by electric cars. Although electric cars themselves have "zero" emissions, to provide the power to recharge the batteries does create pollution from the usual combustion processes, or in the form of radioactive residues when nuclear power plants are employed. Furthermore since lead-acid batteries represent the available proven power source for the present, there is concern over the degree of lead contamination which might result from the increased lead mining, refining, and manufacture of these batteries which the increased use of electric cars requires. Lave et al. (1995) conclude from their study of an electric car replacement scenario that an electric car using batteries with newly mined lead releases 60-times more lead somewhere in the environment per kilometer of use relative to a comparable car burning leaded gasoline. If use of recycled lead and technology goal batteries is assumed, the lead releases are only 5-times the lead emissions per kilometer of travel from the car burning leaded gasoline.. Immediate alternatives to the lead-acid battery to power electric cars are not now available. Nickel-cadmium and nickel metal hydride batteries are much more expensive and contain more highly toxic material than the lead-acid batteries, and do not offer environmental advantages. Sodium-sulfur and lithium-polymer technologies may eventually be attractive alternatives.

There are many problems which are encountered as scientists attempt to achieve some prescribed "acceptable air quality". This has been particularly true in the history of our attempts to control ozone levels in the USA. Calvert et al. (1993) have reviewed this effort recently and their discussion of alternatives for further improvements may prove useful to those who have been assigned new responsibility for developing urban and regional ozone control strategies.

\section{OTHER MAJOR ENVIRONMENTAL CHALLENGES IN ATMOSPHERIC CHEMISTRY}

The perturbations of human activities on the ozone levels in the stratosphere and the troposphere are reasonably well understood today and solutions to these problems continue to be under intensive investigation with the expectation that they can be controlled eventually. But these are only two of the many problems which exist today. Limitations on our time restrict our discussion to only a few other examples which are given in this section.

1) Global warming. Carbon dioxide concentrations have increased $25 \%$ since the beginning of the industrial era. Other "Greenhouse" gases such as methane, the chlorofluorocarbons, etc., have increased as well due to human activity. These gases transmit to the earth's surface the visible, UV and much of the IRradiation from the sun, but, because of their absorption in certain regions of the IR, they trap within the atmosphere some of the infrared radiation which the earth emits as it is warmed by the sun. If carbon dioxide and water vapor were absent in our atmosphere, it is estimated that the average surface temperature would be $-15^{\circ} \mathrm{C}$ rather than the present average of $15^{\circ} \mathrm{C}$. This "Greenhouse" effect is a natural part of the earth, it is a real effect, and increasing concentrations of these gases will cause global warming. The uncertainties in global warming scenarios which exist are the extent and timing of the warming which will result from further increases in greenhouse gases. Like all environmental problems, global warming is a complex function of many variables; e.g., the cloud feedback mechanisms, the circulation of the ocean and the time delay in transferring the heat of the atmosphere to them, etc. Predictions based upon models of global warming are necessarily limited by the assumptions concerning the rate of heat transfer to the oceans and the properties of clouds. However the most sophisticated of the models in use today suggest that if no changes are made in our emissions of greenhouse gases, then the temperature of the earth may rise by up to $1^{\circ} \mathrm{C}$ by the year 2025 and up to $3^{\circ} \mathrm{C}$ by 2100 and that sea level may be rise $0.2 \mathrm{~m}$ by 2030 and $0.65 \mathrm{~m}$ by 2100 . Albritten (1994) has summarized well the motivations for inaction and action to control this problem. Action: 1) A $3^{\circ} \mathrm{C}$ warming would have a huge impact on society; 2) Natural variation would be exceeded-both in rate and in magnitude; 3) Long trace-gas residence times imply a very slow 
reversibility; 4) Some action sooner is easier than any action later. Inaction: 1) The global system is exceedingly complicated; 2) Even the known feedbacks are only crudely represented in current models; 3 ) Major discoveries/surprises are very likely; 4) The generation of greenhouse gases involves the very heart of our modern civilization: power production, transportation, agriculture, etc.

Solutions to the problem of global warming are complex, since they should involve energy conservation by all nations, many of which at this time are reluctant participants in such programs. Also the uncontrolled, or now poorly controlled sources of $\mathrm{CO}_{2}$, such as biomass burning, introduce major problems. It has been estimated by Andreae (1991) that a non-trivial $40 \%$ of the gross $\mathrm{CO}_{2}(26 \%$ of the net $\mathrm{CO}_{2}$ ) emitted into the earth's atmosphere arises from biomass burning.

It seems prudent to maintain an active research program to improve our knowledge of the uncertain areas in global warming, so that our confidence in predictions can be enhanced. Strategies which can help meet the international emission-control plans have been formulated by the 155 nations which met at the United Nations' "Earth Summit" held in Rio de Janeiro in 1992. It now appears that most industrialized nations are unlikely to meet even their short-term goal of reducing the greenhouse gas emissions to the 1990 levels by the year 2000 . The stimulus which will be provided by more accurate model input data with the resulting more reliable model predictions will certainly go a long way to convince us all of the real consequences of inaction and the necessity for a carefully planned action.

2) Acid Deposition. The formation and deposition of acids in the atmosphere has been the subject of extensive studies throughout the world. A large body of evidence shows a widespread problem in Europe and North America, with major impacts on aquatic systems. Effects on terrestrial ecosystems are less clear cut, because of the complexity of the systems themselves. Nevertheless, surface soil acidification and chemical alterations of the soil-water chemistry may well be a primary cause of the phenomenon of forest decline observed in North America and Europe (Hutchinson and Havas, 1994). It is clear from these studies that sulfur dioxide and oxides of nitrogen $\left(\mathrm{NO}, \mathrm{NO}_{2}\right)$ emissions from combustion sources involved in human activities are the dominant precursors of acids present in the air over most continents. As with many of the problems in atmospheric chemistry, the dominant active gas phase agent which transforms these precursors to acids is the $\mathrm{OH}$-radical; the reactions (30)-(33) are important in this case:

30) $\mathrm{OH}+\mathrm{SO}_{2}(+\mathrm{M}) \rightarrow \mathrm{HOSO}_{2}(+\mathrm{M})$

31) $\mathrm{HOSO}_{2}+\mathrm{O}_{2} \rightarrow \mathrm{HO}_{2}+\mathrm{SO}_{3}$

32) $\mathrm{SO}_{3}+\mathrm{H}_{2} \mathrm{O} \rightarrow \mathrm{H}_{2} \mathrm{SO}_{4}$

33) $\mathrm{OH}+\mathrm{NO}_{2}(+\mathrm{M}) \rightarrow \mathrm{HONO}_{2}(+\mathrm{M})$

$\mathrm{H}_{2} \mathrm{O}_{2}$ and $\mathrm{N}_{2} \mathrm{O}_{5}$, formed largely from gas phase chemistry (reactions (27) and $\mathrm{O}_{3}+\mathrm{NO}_{2} \rightarrow \mathrm{NO}_{3}+\mathrm{O}_{2}$; $\mathrm{NO}_{3}+\mathrm{NO}_{2} \rightarrow \mathrm{N}_{2} \mathrm{O}_{5}$ ), both initiate acid generation in cloud-water through the reactions (34)-(36) (Calvert et al., 1985; Mozurkewich and Calvert, 1988; Penkett, 1994).

34) $\mathrm{SO}_{2}+\mathrm{H}_{2} \mathrm{O}$ (cloud water) $\rightarrow \mathrm{HSO}_{3}^{-}$(aq) $+\mathrm{H}^{+}(\mathrm{aq})$

35) $\mathrm{HSO}_{3}^{-}$(aq) $+\mathrm{H}_{2} \mathrm{O}_{2}$ (cloud water) $\rightarrow \mathrm{H}^{+}+\mathrm{SO}_{4}^{2-}+\mathrm{H}_{2} \mathrm{O}$

36) $\mathrm{N}_{2} \mathrm{O}_{5}+\mathrm{H}_{2} \mathrm{O}$ (cloud water) $\rightarrow 2 \mathrm{H}^{+}+2 \mathrm{NO}_{3}^{-}$

A significant fraction of the nitrate found in the soil of the Netherlands is believed to come from the oxidation of a basic compound, ammonia, by microorganisms. Ammonium ions formed from its reaction with acids, oxidize to form nitric acid in (37) (Slanina in Freemantle, 1995):

37) $\mathrm{NH}_{4}^{+}+\mathrm{O}_{2} \rightarrow 2 \mathrm{H}^{+}+\mathrm{NO}_{3}^{-}+\mathrm{H}_{2} \mathrm{O}$

The extent of acid deposition has decreased significantly in the US and in some parts of Europe. A good response to the first phases of lowering of the emission of sulfur and nitrogen oxides has been observed in the lowered sulfate and nitrate deposition. Planning in Europe aims to close the sulfur gap by at least $60 \%$ by 2010 (Freemantle, 1995).

3) Toxic chemicals. Koptyug (1990) identified a number of areas where chemists need to cooperate with scientists from other disciplines in order to make a positive contribution to the long term protection of life on Earth. These include: a) Development of new environmentally safe chemical product from raw materials; 2) Reduction of existing levels of chemical pollutants in the atmosphere, water and land; 3) Study of the transformation of anthropogenic chemical substances in the environment. 4) Prediction of the 
impact of chemical substances on ecosystems, man and climate.

Chemists today are reorienting their thinking in the development of new syntheses. The time-honored tradition of selecting a chemical reaction sequence to maximize the product yields is being supplemented by a new concern for the toxic nature of the raw materials, catalysts, solvents, reagents, by-products, and impurities expected in the process.

\section{CURRENT AND FUTURE PARTICIPATION OF THE IUPAC SCIENTISTS IN THE SOLUTION OF ATMOSPHERIC AND ENVIRONMENTAL CHEMISTRY PROBLEMS}

The author has recently reviewed the activities related to environmental chemistry within the International Union of Pure and Applied Chemistry (Calvert, 1995). Some 338 IUPAC publications of direct or indirect interest to the areas of environmental chemistry have appeared in the 1960 to 1994 period. The reviewer judged many of these to be of significant value to the area of environmental chemistry. Publications authored by scientists in the Analytical Chemistry and Applied Chemistry Divisions account for $68 \%$ of the total, while the other $32 \%$ came from the Physical Chemistry Division (12\%), the Inorganic Chemistry Division (6\%), the Organic Chemistry Division (6\%), the Clinical Chemistry Division (6\%), the Macromolecular Division, the Committee on Chemistry and Industry and the CHEMRAHN Committee (3\%). The increasing interest of IUPAC scientists in the chemistry of the environment and the value of increased collaboration with scientists of different chemical and environmental expertise has encouraged IUPAC reorganization to form a specific division which encompasses studies all of the aspects of Chemistry of the Environment.

Many organizations can use the input of the chemical experts in IUPAC in achieving their goal to protect the health of the people and the environment. For example, the World Health Organization has formulated a new global WHO strategy for environmental health which includes the improvement of technical capabilities for the monitoring and assessment of environmental risks to health, the management of environmental risks to health (i.e., their prevention, abatement, and control). It also gives plans to assess and manage chemical risks and preparedness and response to chemical emergencies. IUPAC scientists have had several cooperative efforts with WHO and our input to such programs should be strengthened in the years ahead.

There are many international and national groups throughout the world which are now actively involved in large environmental studies. Most of these are well-funded research projects which have been designed to solve environmental problems identified by scientists and government leader to be of national or international concern. In fact many IUPAC scientists are themselves actively involved in these large projects. Of course IUPAC is in no position to enter into direct competition with these programs, although its members do now and can continue to contribute substantially to them. We commonly carry out our IUPAC scientific studies with little or no funding from our parent organization. We have come to expect from our efforts little more than critical reviews of published information and scientifically sound recommendation based upon these reviews. Yet this format does provide a good window through which we can pass our contributions to the scientific community. The unique mix of international chemical experts within IUPAC is highly qualified to provide identification and solutions to environmental problems, even though most of the contributions which we make will be limited to paper studies and evaluations. We can identify here several important areas to which IUPAC studies have provided, and will continue to provide, useful information to the atmospheric chemistry community:

1. Former Applied Chemistry Division and the proposed Division of Chemistry of the Environment. These scientists have considerable field experience as well as training in the fundamental sciences, and their input does contribute a significant practical dimension to the important "academic" input from the "pure" scientists. a) Reviews and recommendations for methods of analysis for contaminants in foods, oils, fats, and soils, water, and air; $b$ ) the prediction of the fates of chemicals in the environment; $c$ ) identification of proposed solution to local, regional, national and world-wide environmental problems.

2) Analytical Chemistry Division. The detection and quantification of trace compounds in the environment is the foundation of environmental problem identification and monitoring. Hence the contribution of the analytical chemists has been and will continue to be important to the environmental chemistry studies within IUPAC. These include: a) evaluations of the suitability and limitations on analytical methods and 
instrumentation as now applied to trace air, water, and soil contaminants; b) quality assurance in the environmental chemistry area throughout the world; c) development of new, specific methods for the analysis of trace components.

3) Collaborative studies, intercomparison. Several valuable studies led by scientists in Divisions I, II, V, and VI of IUPAC have focused on instrument and chemical analysis methods intercomparisons. These are designed to test our ability to characterize quantitatively the environmental contaminants, to identify problems, and to offer solutions to these problems. Joint sponsorship has often been required to finance these studies.

4) Evaluated constants required in environmental studies. Workers in the area of environmental sciences, like scientists in all areas, cannot be experts in every fundamental area, nor can they adequately assess the quality, accuracy and reliability of the diverse material from which they must select needed data. Of significant help to the environmental chemist, as well as those in other disciplines, are publications of IUPAC scientists which provide "best values" for the rate constants, solubility data, Henry's law constants, stability constants, optical cross sections in the ultraviolet, infrared and visible regions, and other specific properties of trace impurities in the environment.

5) Reference materials for use in environmental studies. Publications related to the worldwide production of certified reference materials are valuable to environmental scientists. Unfortunately some must prepare their own standards using relatively untested methods with products of questionable quality and stability. Others purchase "standards" from the lowest commercial bidder. National laboratories in several countries have provided reliable samples of some reference materials, although often the low concentration range required for standardization of environmental samples $\left(10^{-6}\right.$ to $10^{-9}$ mole fraction) is not available. It is hoped that a substantial increase in the communication between the IUPAC and other environmental chemists and scientists in the national and other laboratories will stimulate the development of the many new reliable standards required today. IUPAC sponsored comparisons of the similar products obtained from alternative suppliers of standards would help establish the credibility of the providers.

6) The training of environmental scientists in the rapidly developing countries. The need for highly motivated and well-trained scientists in the field of environmental chemistry, particularly in a rapidly developing country, will continue to escalate with that country's economic growth. Problems will arise with the increased use of fossil fuel combustion in transportation, industry, power development, and with increased use of chemicals in agriculture, food preparation, industry, etc. There are many countries in the world that now have little expertise in environmental chemistry, and serious existing problems go unidentified and unsolved. The success of many international environmental programs would be enhanced greatly with the availability of a trained and educated cadre of scientific partners for the expanding network of monitoring stations, international field programs, and in the interpretation of the large data sets that are generated in these activities. In the opinion of this author, the international team of IUPAC scientists, representing all of the fundamental and applied areas of chemistry and with vast experience in University teaching, is as highly qualified as any international body to organize instructional programs in Environmental Chemistry. Indeed, there is strong evidence of the value of past offerings of workshops and courses by IUPAC scientists. In the area of atmospheric chemistry a large cadre of volunteer teachers for training programs has been identified through advertisements in IUPAC, AGU and other journals. These volunteers are now participating in workshops planned for the developing countries. Formal IUPAC sponsored training programs in the subjects related to environmental chemistry, coupled with financial backing from national and international agencies (e.g., WMO, UNESCO, etc.), will be of direct value to developing countries.

7) Proposed criteria for the development of future IUPAC sponsored Environmental Chemistry programs. In the planning of future environmental chemistry projects for IUPAC, this author suggests that the following criteria be satisfied: a) The proposed project should have a reasonably high potential of providing useful data required in the solution of a recognized environmental problem; b) The project should utilize well the variety of scientific talent now within IUPAC together with those scientists which we co-op as consultants; c) The study should be consistent with the limited financial resources of IUPAC; d) The project should provide a unique product which is not now being supplied adequately by other scientific bodies. 


\section{E. SUMMARY}

As the economies of the rapidly developing countries grow and as new technologies appear in all of our societies, the identification of perturbations induced in the chemistry of our atmosphere, and in the environment in general, will become increasingly important. Furthermore the understanding of the fundamental chemistry of the effects induced will be a crucial part of the development of scientifically sound emissions control strategies for the impurities which lead to these perturbations. In the process of development of sound environmental policies, it is suggested that a high priority be placed on the involvement of interested IUPAC scientists in the many chemical disciplines. IUPAC's unique international mix of chemists from a large variety of workplaces, academic, industrial, government, and private sectors, offers a pool of expertise which is uniquely qualified to apply fundamental principles to the solutions of environmental problems and to train scientists in the developing countries in the basic and applied areas of the environmental chemistry.

\section{REFERENCES}

AFEAS Workshop, Proceedings of the workshop on the atmospheric degradation of HCFCs and HFCS, Nov., 1993, Boulder, CO, sponsored by National Aeronautics and Space Administration, The National Oceanic and Atmospheric Administration, and the Alternative Fluorocarbons Environmental Acceptability Study, March, 1995.

Akimoto, H., Nakane, H., and Y. Matsumoto, The chemistry of oxidant generation: tropospheric ozone increase in Japan, in Chemistry of the atmosphere: The impact of global change, Ed. J. G. Calvert, Blackwell Scientific Publications, 1994, pp. 261-273.

Albritten, D. L., Atmospheric chemistry and global change: the scientist's viewpoint, chapter 1 in The chemistry of the atmosphere: Its impact on global change, Ed. J. G. Calvert, Blackwell Scientific Publications, 1994, pp. 3-9.

Beaton, S. P., Bishop, G.A., Zhang, Y., Ashbaugh, L. L. Lawson, D. R., and Stedman, D. H., On-road vehicle emissions: regulations, costs and benefits, Science, 268, 991-993, 1995.

Calvert, J. G., Review of the activities related to environmental chemistry within the International Union of Pure and Applied Chemistry, 1995, report available from the Secretariat of the IUPAC, Bank Court Chambers, 2-3 Pound Way, Templars Square, Cowley, Oxford, OX4 3YF, UK.

Calvert, J. G., Lazrus, A., Kok, G. L., Heikes, B. G., Walega, J. G., Lind., J., and Cantrell, C. A., Chemical mechanisms of acid generation in the troposphere, Nature, 317, 27-35, 1985.

Calvert, J. G., Heywood, J. B., Sawyer, R. F., and Seinfeld, J. H., Achieving acceptable air quality: some reflections on controlling vehicle emissions, Science, 261, 37-45, 1993.

Cantrell, C. A., Shetter, R. E., Calvert, J. G., Parrish, D. D., Fehsenfeld, F. C., Goldan, P. D., Kuster, W., Williams, E. J., Westberg, H. H., Allwine, G., Martin, R., Peroxy radicals as measured in ROSE and estimated from photostationary state deviations, J. Geophys. Res., 98, 18355-18366, 1993.

Freemantle, M., The acid test for Europe, Chem. \& Eng. News, May 1, 1995, pp. 10-17.

Haagen-Smit, A. J., Chemistry and physiology of Los Angeles Smog, Ind. Eng. Chem., 44, 1342-1346,1952.

Haagen-Smit, A. J., and Fox, M. M., Automotive exhaust and ozone formation, S. A. E. Trans., 63, 575-580, 1955.

Hutchinson, T. C., and Havas, M., Ecological impacts of acid deposition, in The chemistry of the atmosphere: Its impact on global change, Ed. J. G. Calvert, Blackwell Scientific Publications, 1994, pp. 297-315.

Kley, D., Geiss, H. and Mohnen, V. A., Concentrations and trends of tropospheric ozone and precursor emissions in the USA and Europe, in The chemistry of the atmosphere: Its impact on global change, Ed. J. G. Calvert, Blackwell Scientific Publications, 1994, pp. 245-259.

Kuptyug, V., Chemistry and the environment: The IUPAC programme, Ed. M. H. Freemantle, printed by Rocardo Press Ltd., Didcot, England, 1990.

Molina, M. J., The probable role of stratospheric "ice" clouds: Heterogeneous chemistry of the "ozone hole", in The chemistry of the atmosphere: Its impact on global change, Ed. J. G. Calvert, Blackwell Scientific Publications, 1994, pp. 27-38.

Molina, M. J., and Rowland, F. S., Stratospheric sink for chlorofluoromethanes: chlorine-atom catalyzed destruction of ozone, Nature, 249, 810-814, 1974.

Mozurkewich, M., and Calvert, J. G., Reaction probability of $\mathrm{N}_{2} \mathrm{O}_{5}$ on aqueous aerosols, J. Geophys. Res., 93, $15889-15896,1988$.

NASA, The atmospheric effects of stratospheric aircraft: A fourth program report, NASA Reference Publication 
1359, Edited by: R. S. Stolarski and W. L. Wesoky, 1995.

NRC, U.S. National Research Council, Rethinking the ozone problem in regional air pollution, National Academy Press, Washington, D.C., 1991.

NRC, U. S. National Research Council, The atmospheric effects of stratospheric aircraft: Interim assessment report of the NASA high-speed research program, Panel on atmospheric effects of stratospheric aircraft, June, 1993.

Penkett, S. A., Atmospheric photochemistry and its role in generation of acidity in rain, Chapter 24, in The chemistry of the atmosphere: Its impact on global change, Ed., J. G. Calvert, Blackwell Scientific Publications, 1994, pp. 327-343.

Seinfeld, J. H., Ozone air quality models: A critical review, JAPCA, 38, 616-645, 1988.

WMO, Scientific assessment of ozone depletion: 1994, Report No. 37, World Meteorological Organization, Global Ozone Research and Monitoring Project, assessment co-chairs, D. L. Albritton, R. T. Watson, and P. J. Aucamp, published by the World Meterorological Organization, P.O. Box 2300, Geneva, Switzerland, 1995. 